\title{
AI-based Strategic Marketing: SMAI Model
}

\author{
Praneet Amul Akash Cherukuri*, Sai Kiran Vududala, Nishanth Raju Saraswathi, Jahanavi Sanda \\ Dept. of Computer Science and Engineering, CMR Institute of Technology, Hyderabad, India \\ chamu191@gmail.com, saikiran37544@gmail.com, nishanthraju2001@gmail.com,jahanavisanda30@gmail.com
}

\begin{abstract}
One of the important factors that play a vital role in the success of a business is marketing. Marketing has seen multiple changes throughout the decades in the Definition, Organization, and Implementation processes. With the advent of technology, especially Artificial intelligence many sectors underwent a great amount of transformation to get themselves equipped with the latest technological innovations. The business sector was also on the same lines with other sectors in this period of change. Marketing being a very theoretical and humanized concept it was pretty hard at first to incorporate changes accordingly. Later the scope for marketing enlarged and it slowly started making an entrance into inculcating the latest technologies. In this paper, the researcher studies the particularities of marketing and its integration with artificial intelligence, providently proposing a machine learning-based model (SMAI) involving strategic marketing decision making.

Index Terms-Artificial Intelligence, Marketing, Business, Strategic Marketing, Machine Learning
\end{abstract}

\section{INTRODUCTION}

$\mathrm{T}$ HE CORE of a business's approach to reaching its customer is through marketing. Throughout the evolution of Business, many primary ailments of business kept changing with the change of the human mind and the way in dealing with business. But marketing always had it stand and was one of the primary sectors of business that was so consistent in the success of a business. With many new strategies being proposed in the sector of marketing it soon became one of the main branches of business and has greatly influenced people in making their final decisions. Usually, Marketing can be termed as influencing a person about the brand or educating oneself about the product to its fullest form strategically and interestingly. With the advent of technology, many sectors brought about a great change by formalizing and reevaluating their processes with technology and therefore increasing their efficiency. Though this same concept was continuously applied in the field of Marketing there was not much of a change or growth in business due to the unnoticed analytics that was greatly required for marketing.

Strategic Marketing was another such highlight that brought in a great change to the way marketing was dealt, and another dimension of thought was proposed to carefully strategize how a product was marketed, this strategy was physically done by humans and was an everyday job. When Artificial Intelligence came into existence, it shed light on many unnoticed facts and processes that were stagnant or were processes that were repetitive and showed a way to make it automatic and less time-consuming. This intelligent decision making and intuitive thinking through different dimensions made it a great choice to introduce it in the field of Marketing. Since the analytical analysis aligned with both the fields, it chose business much clearer to choose AI in the field of marketing. [1]

\section{Prevalent System \& InNovations Brought THROUGH AI}

Many systems came into existence with the advent of AI and hence multiple processes and algorithms were used to intelligently process and generate data that could generate greater leads in marketing and other management areas. Below are three business institutions that brought in a change in how they did Marketing and were successful in their journey.

\section{A. Chase Bank}

After a study with Persado, Chase Bank found that their approach to copywriting was very different from that produced by an Artificial Intelligence model. After they have compared their work with the model it was seen that the content provided by the model felt more humane and attracted more customers than their usual records show.[4]

\section{B. Starbucks}

Predictive Analytics, a form of AI was used by Starbucks which collects data from their loyalty cards and app and processes this data to achieve personalized recommendations through which it can push notifications to its customers on a much-individualized approach. Similarly, a study by Aberdeen suggested that companies that used predictive analytics in their marketing increased their organic revenue by approximately $21 \%$.[2]

\section{Nike}

Nike improved its customer engagement by creating an application "Nike Maker Experience" that will give its customers an experience of customizing their shoes and hence improving their customer likeliness towards their products. In extension, they have stored the data and used machine learning algorithms to personally generate user recommendations that showed up in their accounts and improved their overall sales.[5] 


\section{Proposed Model - SMAI Model}

Businesses have often faced ambiguity in the decision of introducing $\mathrm{AI}$ into their marketing strategy. A proper structure on how and what process of AI to introduce and what process could help in the increase of a particular type of business is a very tiresome process for business due to the lack of ability to understand. To compensate these companies are looking towards hiring data scientists and special AI teams to get a more clear understanding. In contrast to this in this research, we propose a Simple Marketing Artificial Intelligence (SMAI) Model that will help and guide companies to make intelligent decisions and develop their marketing strategies using AI and improve their sales. The model is built to understand any business needs and could analyze all the needs and recommend a proper AI strategy that could boost marketing and show an increase in sales. The result generated is not a single strategy but a group of strategies and what processes of $\mathrm{AI}$ and to what extent must be used in comparison to the previous strategies. From the above model, we could evaluate how the process could help us consider our options. The model consists of four phases, they are:

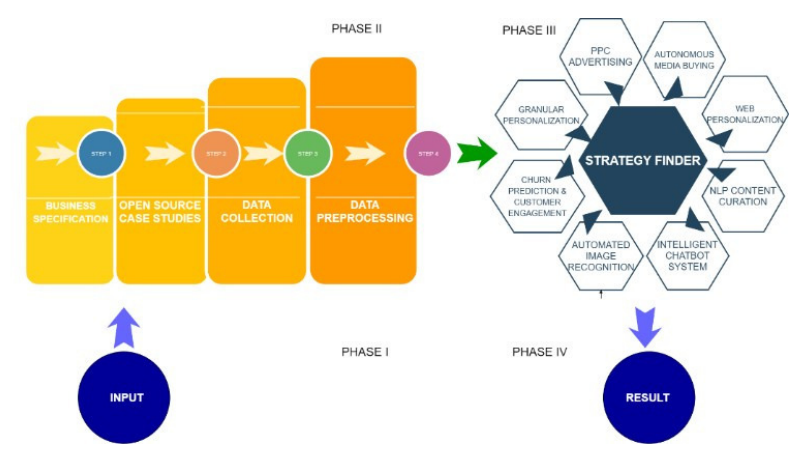

Fig.1. Bar Chart Representation of Increase \& Decrease in revenue by various sectors during COVID-19

\section{A. Phase I}

In the first phase, input to the model is taken. The input to the model is mainly interfaced with the business model requirements about how the business works and what factors enable the betterment of the company. Important data that could help the model in outlining and helps in deciding to use a particular strategy are taken as indents. These indents are predetermined and are defined according to the various business models and types in the domains they exist. The input is taken in the form of a lengthy structure that clearly outlines every problem and since every business is everchanging the need for a real-time model is necessary. Hence the data input is always dynamic and updates itself according to the changes made to the business model.

\section{B. Phase II}

The next phase focuses on the processing of the data through four various steps. These steps evaluate and outline the indents and trends through four various steps and preprocess and tag them with various machine learning algorithms and open-source data mapping to the real world. The business data and informatics is mapped to real-world opensource case studies and the particular data about that company or firm is retrieved. The phase consists of four different steps, the first step is permitted to analyze the business's information and remove it. Then the data is processed through the tagging system to the case studied and related data is tagged. Recommendation system technology using Bayesian classifiers can be used to determine the best data that could be tagged and curtained [3].Then in the next step, the data tagged is retrieved and moved to the next step for processing. In the next step, the data is processed and cleaned to send it for the strategy maker in which the data is used to make the final decisions.

\section{Phase III}

The next phase focuses on the processing of the data through four various steps. These steps evaluate and outline the indents and trends through four various steps and preprocess and tag them with various machine learning algorithms and open-source data mapping to the real world. The business data and informatics is mapped to real-world opensource case studies and the particular data about that company or firm is retrieved. The phase consists of four different steps, the first step is permitted to analyze the business's information and remove it. Then the data is processed through the tagging system to the case studied and related data is tagged. Then in the next step, the data tagged is retrieved and moved to the next step for processing. In the next step, the data is processed and cleaned to send it for the strategy maker in which the data is used to make the final decisions.

\section{1) Granular Personalization}

Marketing messages are generally be educated by a Client's advantages, buy history, area, past brand connections, and a large group of other information points.AI helps the marketing groups go past standard segment information to find out about customer inclinations on a granular, singular level. This assists brands with making curated encounters dependent on a client's interesting tastes.

2) AI-enhanced PPC Advertising

Pay per click advertising is one of the most huge markets in which many brands invest to increase their brand reach. With the advent of AI to understand and recommend new channels to advertise that may not have been or being used by the competitors in the market.

\section{3) Autonomous Media buying}

Digital Media buying is a process of autonomously buying paid ad campaigns that could help in achieving greater customer throughput. Automatic stages influence AI to offer an advertisement space pertinent to target crowds progressively. The offer is educated by information, for example, interests, area, buy history, purchaser expectation, and that's only the tip of the iceberg. This empowers promoting groups to focus on the correct channels at the right time, at a 
serious cost. Automatic purchasing represents how AI can expand showcasing adaptability to address clients as their issues and interests develop.

4) Custom Web Personalization

Custom website personalization helps in enhancing the visitor experience with custom personalization to the website. By investigating much information that focuses on a solitary client (counting area, socioeconomics, gadget, collaboration with the site, and so on.), AI can show the bestfitting offers and substance. Another factor is the message pop-ups that can be explicit to singular clients, conveying them the perfect message at the perfect time.

\section{5) NLP Content Curation}

Natural Language processing plays a pivotal role in the content curation of the marketing material. As known for its great accuracy many NLP models are developed to understand the sentiment of the customers and precisely recommend better content personalized to the user. Some of the best examples where intelligent content curation could be widely used are Business Descriptions, Advertisement for Marketing Content.

6) Intelligent Chatbot System

From style to wellbeing to protection, AI chatbots are giving marginal enchantment client assistance. Also, now and again, they're greater at making customized content than people. Chatbots approach a large number of client-focused information focuses. They can likewise total area explicit solicitations to distinguish designs, spot dull issues, and foresee what's causing issues for a specific client.

7) Automated Image Recognition

Picture acknowledgment could mean better match up between online substance and store visits. Numerous stores utilize facial-acknowledgment programming to follow clients' in-store visits and connect these recordings to their clients' profiles. The information assembled from in-store facial acknowledgment includes another layer - a huge layer - to alter the substance experience for your store guests. Realizing how the individual shops empower you to make and convey much more focused on one-on-one informing. Facial acknowledgment programming additionally can be utilized as an estimation instrument.

8) Churn Prediction \& Customer Engagement

AI calculations likewise can help recognize withdrawn client sections that are going to stir or leave for a contender. Artificial intelligence controlled devices in this class can help assemble information, fabricate a prescient model, and test and approve that model on genuine clients. That data can demonstrate what phase of agitating the individual is in. While speedy beats (clients who desert an item soon after beginning to utilize it) are hard to reconnect, late-stir clients (the individuals who have a dependable connection with your image) can be boosted to continue utilizing your item. At the point when joined with customized content creation, AI-fueled stir expectation helps keep a greater amount of your clients drawn in, prompting higher lifetime worth and benefits. As the agitated expectation is extraordinary to each item and friends, the AI calculations should be balanced for your organization or worked from the beginning. With that data, you can make a more successful substance to be conveyed to separated clients.

\section{Phase IV}
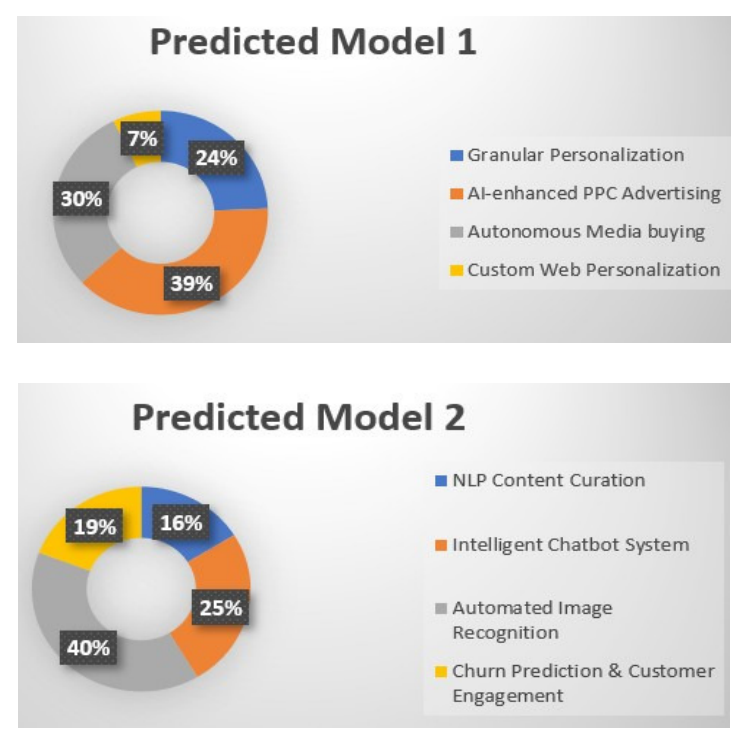

Fig 2. Representation of the predicted model

After going through the rigorous strategy finding the model would then output a result that is a form of multiple processes that could produce a greater strategy using different AI models and processes and deal in getting a greater accuracy and attracting customers. The output is usually shown in the form of 3 or more accurate process that could help the business boost its business by using the said AI strategies. The models also show at what percentage that particular AI should be used to receive the best outcome and could help in determining the correct usage.

\section{CONCLUSION}

In conclusion, it is time and again proved that the use of AI in marketing benefits the business in one or the other way. The model proposed in the research directly aims to help businesses not capable of making their own decisions as well as business that are already into AI marketing but are unsure of how and what strategies to proceed with. With a unified result of multiple strategies and properly analyzing the business specification and comparing it with the existing case studies, the model is efficient enough to recommend the best possibilities for the business. In an analysis to understand the revenue benefits of business in the light of AI in marketing, the below graph (Fig.3) clearly depicts that there has been a steady increase in the revenue markets once the use of $\mathrm{AI}$ is implemented and intelligent marketing is done. [6] 


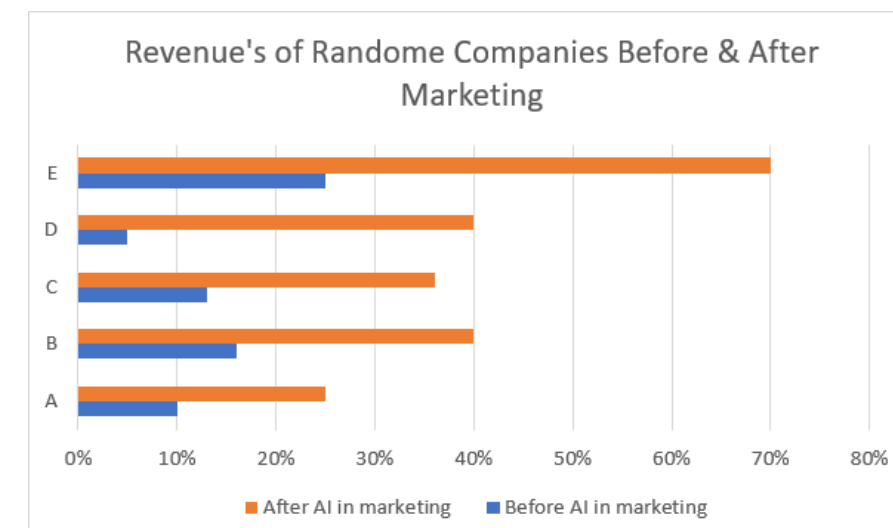

Fig 3. Bar Chart depicting the difference in revenues before and after use of AI

\section{REFERENCES:}

[1] Jarek, Krystyna \& Mazurek, Grzegorz. (2019). Marketing and Artificial Intelligence. Central European Business Review. 8. 46-55. $10.18267 / j . c e b r .213$.

[2] 4 Ways Predictive Analytics Can Boost Your Sales. (2019, February 21). Retrieved from https://www.aberdeen.com/big-dataproessentials/4-ways-predictive-analytics-can-boost-sales/

[3] Cherukuri, Praneet Amul Akash. (2019). Recommender System For Educational Analysis In Prediction of Appropriate Career \& Domain Recommendations using Machine Learning Techniques. International Journal of Machine Learning and Networked Collaborative Engineering. 03. 135-142. 10.30991/IJMLNCE.2019v03i03.002.

[4] JPMorgan Chase Announces Five-Year Deal with Persado For AIPowered Marketing Capabilities. (2019, July 29). Retrieved October 10, 2020, from https://www.persado.com/press-releases/jpmorganchase-announces-five-year-deal-with-persado-for-ai-poweredmarketing-capabilities/

[5] New Live-Design Experience Promises Custom Shoes in Less Than 90 Minutes. (2017, September 05). Retrieved October 10, 2020, from https://news.nike.com/news/nike-makers-studio

[6] Davenport, T., Guha, A., Grewal, D. et al. How artificial intelligence will change the future of marketing. J. of the Acad. Mark. Sci. 48, 24-42 (2020). https://doi.org/10.1007/s11747-019-00696-0

[7] Singh, R., Anita, G., Capoor, S., Rana, G., Sharma, R., \& Agarwal, S. (2019). Internet of Things Enabled Robot Based Smart Room Automation and Localization System. In Internet of Things and Big Data Analytics for Smart Generation (pp. 105-133). Springer, Cham. ISBN 978-3-030-04203-5 